\title{
ローダミン Bによるスズのけい光定量
}

\author{
西川 泰治, 平木 敬三, 長 沼 健, 新名 昭三*
}

(1970 年 2 月 16 日受理)

\begin{abstract}
スズ (IV) は臭化水素酸酸性からローダミンB試薬によりベンゼン, トルエンで抽出され, 安定なけ い光を発し，そのけい光スペクトルは 530〜630 $\mathrm{m} \mu$ にあることを見いだした。このけい光を利用して スズのけい光定量の基礎検討を行なった。ローダミン B-ブロモスズ酸イオン会合体をベンゼンで抽出 した場合が感度が最もよい. $2 N$ 臭化水素酸より $0.5 \%$ ローダミン B 溶液 $1.5 \mathrm{~m} l$ を加え, $5 \mathrm{ml}$ のべ ンゼンで抽出すれば $0.5 \sim 10 \mu \mathrm{g} \mathrm{Sn} / 5 \mathrm{ml}$ のスズが誤差 $\pm 2 \%$ 以内で定量できた. インジウム，タリ ウム，金が同系よりベンゼンに抽出され妨害する。あらかでめタリウム以外のこれらイオンよりスズを 硫化水素により沈殿分離し（担体としてカドミウムを使用），ついで $4 N$ 臭化水素酸酸性よりローダミ ン B-ブロモタンイトイオン会合体をベンゼンで抽出分離し, 水相の酸濃度を $2 N$ 臭化水素酸酸性とし て，ローダミンBーブロモスズ酸イオン会合体をベンゼンで抽出，けい光定量すればタリウムの影響よ り免れる.
\end{abstract}

\section{1 緒言}

微量のスズの定量法としてジチオール1)，フェニルフ ルオロン2) による吸光光度法, フラボノール3)，モーリ ン4)によるけい光法, ポーラログラフ法5)など各種の方 法が用いられている。 また最近, Arnesen6) はローダミ ン Bを用いてスズを吸光光度定量する方法を報告してい

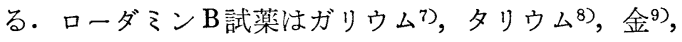
アンチモン10)などとイオン会合体を生成し適当な有機溶 媒に抽出されるので，これら金属イオンの吸光度定量な らびにけい光定量に賞用される. 著者らはローダミン B で代表されるキサンテン系色素による各種金属イオンの けい光定量法汇関する一連の研究を遂行中であるが，そ の際，スズがローダミンB試薬により臭化水素酸酸性か らベンゼン，トルエンに抽出され，けい光を発すること を見いだした．このローダミンBーブロモスズ酸イオン 会合体のけい光はガリウム，タリウム(III) などのイオ ン会合体のけい光と比較す机ば弱い。しかし，このけい 光を利用したスズの定量法はフラボノールによるスズの けい光定量法と同程度の感度を有しすぐれている。 本法はローダミン Bによる吸光光度法(定量範囲 : 0.3〜 $0.7 \mathrm{mg} / 20 \mathrm{~m} l)$ と比較すればきわめて高感度であり, 適 当な前処理を施せば実試料の分析に適している.

$*$ 近畿大学理工学部化学教室 $:$ 大阪府東大阪市小若江
2 試薬および装置

\section{$2 \cdot 1$ 試薬}

ローダミンB 溶液 : ローダミン B $1.25 \mathrm{~g}$ を温水に溶 解し $250 \mathrm{ml}$ となるように水で希釈して， $0.5 \%$ 水溶液 として使用した。

スズ標準溶液：塩化第一スズ 2 水塩 $0.1901 \mathrm{~g}$ を濃 塩酸 $25 \mathrm{~m} l$ に溶解後, 水で $100 \mathrm{ml}$ に希釈し $1 \mathrm{mg}$ $\mathrm{Sn}^{2+} / \mathrm{m} l$ 溶液を調製（スズの標定はヨウ素滴定法によ った)，必要に応じて希䣋して用いた。

溶媒：ベンゼン，トルェン，キシレンなどはすべて市 販品を蒸留して用いた ${ }^{11)}$.

\section{2 装 置}

けい光強度の測定には日立製 EPU-2A 型分光光度計 に G-3 型けい光付属装置を組み合わせて使用した（キ セノンランプ：150W 使用). また吸光度測定には日立 製 139 型分光光度計を用いた。

\section{3 定量条件の検討}

\section{1 一般操作法}

スズ一定量に $0.5 \%$ ローダミン B 溶液の一定量を加 光，所定の酸濃度に調節し，水相の全容を $5 \mathrm{ml}$ とす る. これに等量の有機溶媒を加光数分間振り混ぜる. 水 相を分離後有機溶媒相を遠心分離器で脱水し，最適波長 を用いて $0.168 \mu \mathrm{g}$ ローダミン $\mathrm{B} / \mathrm{m} l$ 標準溶液のけい光 強度を対照にとのけい光強度を測定する。 


\section{2 励起, けい光スペクトル}

水相，有機溶媒相の組み合わせを臭化水素酸-ベンゼ ン系，臭化水素酸ートルエン系，臭化水素酸-キシレン 系, 塩酸-ベンゼン系, 塩酸-トルエン系および塭酸-キ シレン系とし，各系の励起，けい光スペクトルを求めた 結果を Fig. 1，Fig. 2 に示した. いずれの系において も，最大励起波長 555〜 565 $\mathrm{m} \mu$ ，またけい光中心波長は $570 \sim 580 \mathrm{~m} \mu$ と比較的よく似たスペクトルを与える.

\section{3 酸の種類ならびに酸濃度の影響}

各種溶媒に対する酸濃度の影響について検討した結果 を Fig. 3 および Fig. 4 に示した.これよりわかるよう に塩酸系よりも臭化水素酸系のほうが抽出されやすく， また溶媒種としてはベンゼン，トルエンがすぐれている ことを知った．Fig. 4 に示したように $2 N$ 臭化水素酸 酸性よりベンゼン抽出すれば，他の系よりもけい光強度 が強く好つごうである.

\section{4 試薬量の影響}

ローダミン $\mathrm{B}$ 溶液の使用量とけい光強度との関係を $2 N$ 臭化水素酸-ベンゼン系について求めた結果を Fig. 5 に示す. スズ $10 \mu \mathrm{g}$ までの濃度の試料溶液については $0.5 \%$ ローダミン B 溶液 $1.5 \mathrm{ml}$ の添加でじゅうぶんで あった．他の系についても検討したが，同様の結果が得 られた。

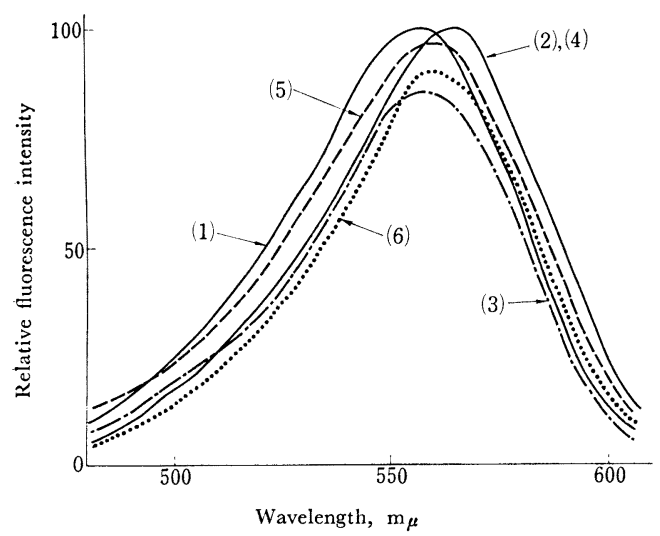

Fig. 1 Excitation spectra of Rhodamine B-tin complexes

(1) $\mathrm{HCl}-\mathrm{C}_{6} \mathrm{H}_{6}$ system, emission wavelength set at $575 \mathrm{~m} \mu$; (2) $\mathrm{HBr}-\mathrm{C}_{6} \mathrm{H}_{6}$ system, emission wavelength set at $580 \mathrm{~m} \mu$; (3) $\mathrm{HCl}-\mathrm{C}_{6} \mathrm{H}_{5} \mathrm{CH}_{3}$ system, emission wavelength set at $570 \mathrm{~m} \mu$; (4) $\mathrm{HBr}-\mathrm{C}_{6} \mathrm{H}_{5} \mathrm{CH}_{3}$ system, emission wavelength set at $580 \mathrm{~m} \mu$; (5) HCl$\mathrm{C}_{6} \mathrm{H}_{4}\left(\mathrm{CH}_{3}\right)_{2}$ system, emission wavelength set at 575 $\mathrm{m}_{\mu}$; (6) $\mathrm{HBr}-\mathrm{C}_{6} \mathrm{H}_{4}\left(\mathrm{CH}_{3}\right)_{2}$ system, emission wavelength set at $575 \mathrm{~m} \mu$

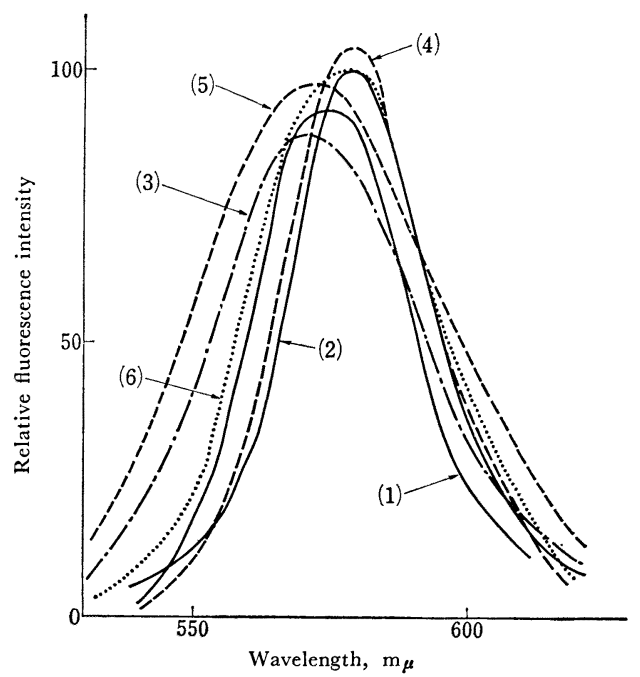

Fig. 2 Emission spectra of Rhodamine B-tin complexes

(1) $\mathrm{HCl}-\mathrm{C}_{6} \mathrm{H}_{6}$ system, excitation wavelength set at $560 \mathrm{~m}_{\mu} ;$; (2) $\mathrm{HBr}-\mathrm{C}_{6} \mathrm{H}_{6}$ system, excitation wavelength set at $565 \mathrm{~m}_{\mu} ;$ (3) $\mathrm{HCl}-\mathrm{C}_{6} \mathrm{H}_{5} \mathrm{CH}_{3}$ system, excitation wavelength set at $555 \mathrm{~m} \mu ;(4) \mathrm{HBr}-\mathrm{C}_{6} \mathrm{H}_{5} \mathrm{CH}_{3}$ system, excitation wavelength set at $565 \mathrm{~m}_{\mu}$; (5) $\mathrm{HCl}$ $\mathrm{C}_{6} \mathrm{H}_{4}\left(\mathrm{CH}_{3}\right)_{2}$ system, excitation wavelength set at $560 \mathrm{~m}_{\mu} ; \quad$ (6) $\mathrm{HBr}-\mathrm{C}_{6} \mathrm{H}_{4}\left(\mathrm{CH}_{3}\right)_{2}$ system, excitation wavelength set at $560 \mathrm{~m} \mu$

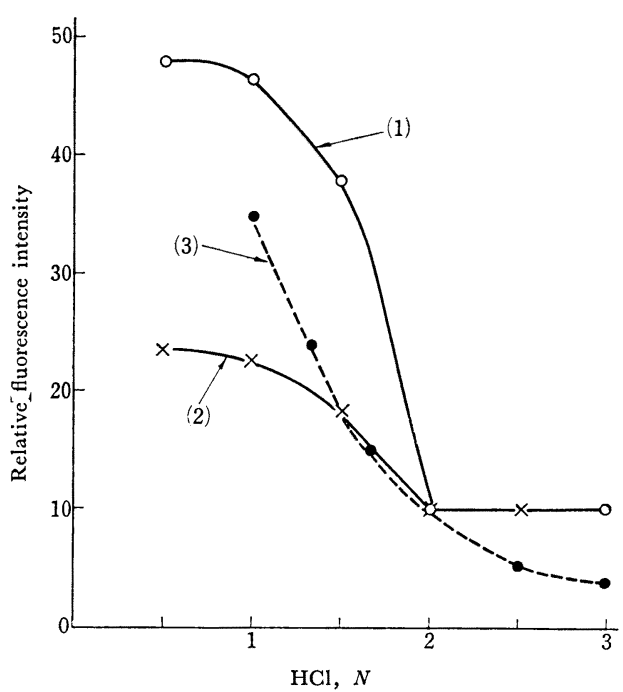

Fig. 3 Effect of hydrochloric acid concentration on fluorescence intensity

(1) $\mathrm{Sn} 30 \mu \mathrm{g}, \mathrm{C}_{6} \mathrm{H}_{6}$, Fluorescence intensity expressed as ratio compared with Rhodamine $\mathrm{B}$ solution $(0.168$ $\mu \mathrm{g} / \mathrm{ml})(560 \mathrm{~m} \mu / 575 \mathrm{~m} \mu$, fluorometer reading was set at 10 div.); (2) $\mathrm{Sn} 30 \mu \mathrm{g}, \mathrm{C}_{6} \mathrm{H}_{5} \mathrm{CH}_{3}\left(555 \mathrm{~m}_{\mu} / 570\right.$ $\mathrm{m}_{\mu}, 30$ div. $)$; (3) $\mathrm{Sn} 30 \mu \mathrm{g}, \mathrm{C}_{6} \mathrm{H}_{4}\left(\mathrm{CH}_{3}\right)_{2}\left(560 \mathrm{~m}_{\mu} /\right.$ $575 \mathrm{~m} \mu, 100$ div.) 


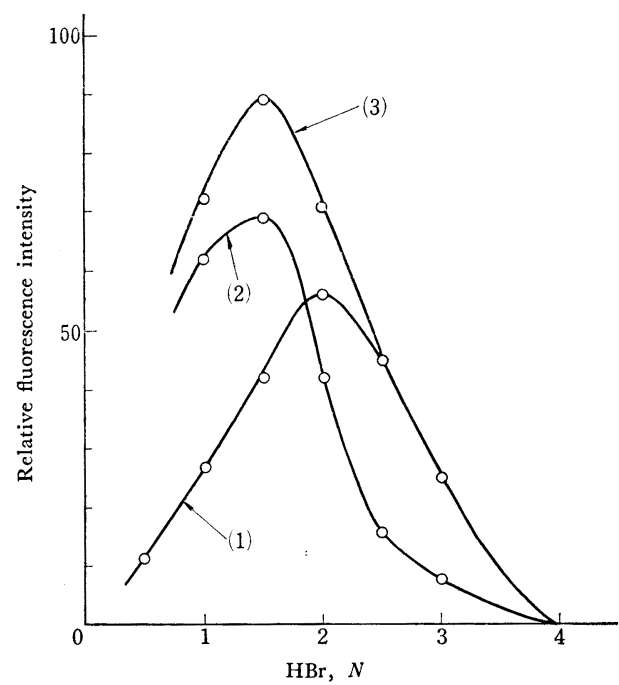

Fig. 4 Effect of hydrobromic acid concentration on fluorescence intensity

(1) $\mathrm{Sn} 20 \mu \mathrm{g}\left(\mathrm{C}_{6} \mathrm{H}_{6}, 565 \mathrm{~m} \mu / 580 \mathrm{~m} \mu, 10\right.$ div. $)$; (2) Sn $20 \mu \mathrm{g}\left(\mathrm{C}_{6} \mathrm{H}_{5} \mathrm{CH}_{3}, 565 \mathrm{~m} \mu / 580 \mathrm{~m} \mu, 20\right.$ div. $)$; (3)

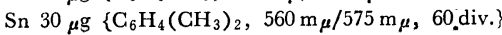

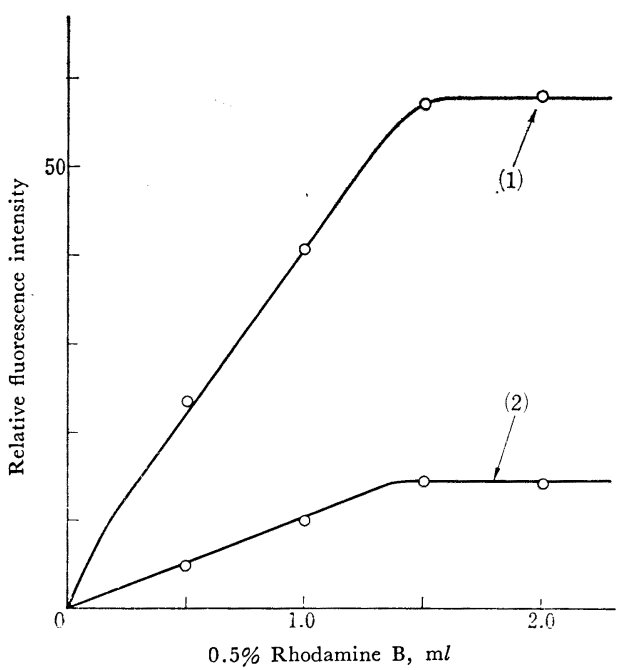

Fig. 5 Effect of reagent concentration (1) Sn $10 \mu \mathrm{g}\left(\mathrm{HBr}-\mathrm{C}_{6} \mathrm{H}_{6}\right.$ system, $565 \mathrm{~m} \mu / 580 \mathrm{~m} \mu$, 10 div.); (2) Reagent blank

\section{5 放置時間の影響}

水相と有機溶媒相の振り混ぜ時間を検討したところ, 振り混ぜ数 200 回/分の振り混ぜ機で 1〜2 分振り混ぜ ればじゅうぶんであった. 振り混ぜ，分離，脱水後のけ い光強度の経時変化を検討した結果を Fig. 6 に示した.

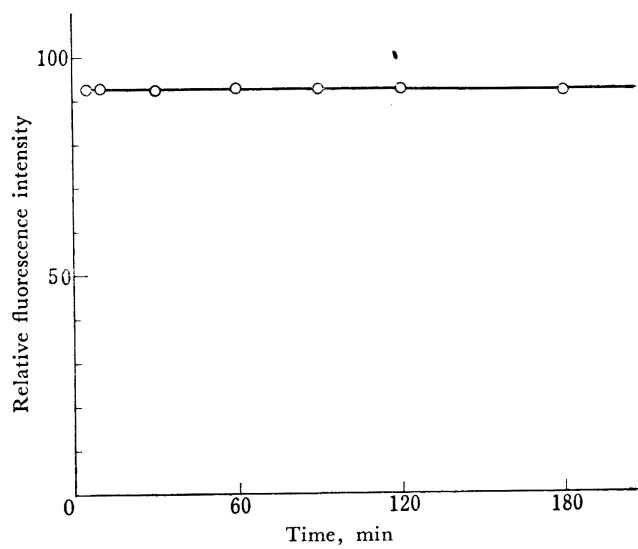

Fig. 6 Stability of fluorescence intensity of Rhodamine B-tin complex Sn $10 \mu \mathrm{g}\left(\mathrm{HBr}-\mathrm{C}_{6} \mathrm{H}_{6}\right.$ system, $565 \mathrm{~m} \mu, 20$ div. $)$

このイオン会合体は少なくとも抽出後 3 時間は室温で安 定であった。

\section{6 検量線}

以上の諸条件の検討結果を基にして各系の最適条件下 (Table I に示す) で $3 \cdot 1$ に示す一般操作法により検量 線を求めた結果を Fig. 7 に示す. Fig. 7 よりわかるよ うに臭化水素酸系では抽出有機溶媒種としてベンゼンを 用いた場合が最も感度がよく，トルエン，キシレンがこ れにつぐ. 塩酸系は感度が低く, かつ試薬ブランク值 も高いので実用化しがたい，臭化水素酸-ベンゼン系を 用いて $0.5 \sim 10 \mu \mathrm{g}$ スズ $/ 5 \mathrm{ml}$ ベンゼンの定量が誤差 $\pm 2 \%$ 以内で可能であった. 試料溶液としてスズ (II), スズ (IV) いずれを使用しても同じ結果が得られた。た とえばスズ (II)，スズ (IV)の $5 \mu \mathrm{g}$ を用い，0.168 $\mu \mathrm{g}$ ローダミン $\mathrm{B} / \mathrm{m} l$ 溶液 20 目盛セットを対照にそのけい 光強度を測定したところ，けい光強度值としてそれぞ れ，60.5，61.0を得た。これはスズ (II) が抽出中に スズ (IV) に酸化されるためであると考えられる6).

Table I Optimum fluorescence conditions of tin complexes

\begin{tabular}{lccccc}
\hline Organic phase & $\begin{array}{c}\text { Aqueous } \\
\text { phase }\end{array}$ & $\begin{array}{c}\text { Excitation } \\
\text { wavelength } \\
(\mathrm{m} \mu)\end{array}$ & $\begin{array}{c}\text { Max. fluo- } \\
\text { rescence } \\
\text { wavelength } \\
(\mathrm{m} \mu)\end{array}$ & $\begin{array}{c}0.5 \% \\
\text { Rhodamine } \\
\text { B used } \\
(\mathrm{m} l)\end{array}$ \\
\hline $\mathrm{C}_{6} \mathrm{H}_{6}$ & 2 & $N \mathrm{HBr}$ & 565 & 580 & 1.5 \\
& 1 & $N \mathrm{HCl}$ & 560 & 575 & 1.0 \\
$\mathrm{C}_{6} \mathrm{H}_{5} \mathrm{CH}_{3}$ & 1 & $N \mathrm{HBr}$ & 565 & 580 & 1.5 \\
& 1 & $N \mathrm{HCl}$ & 555 & 570 & 2.0 \\
$\mathrm{C}_{6} \mathrm{H}_{4}\left(\mathrm{CH}_{3}\right)_{2}$ & $1.5 N \mathrm{HBr}$ & 560 & 575 & 2.0 \\
& 1 & $N \mathrm{HCl}$ & 560 & 575 & 2.0 \\
\hline
\end{tabular}




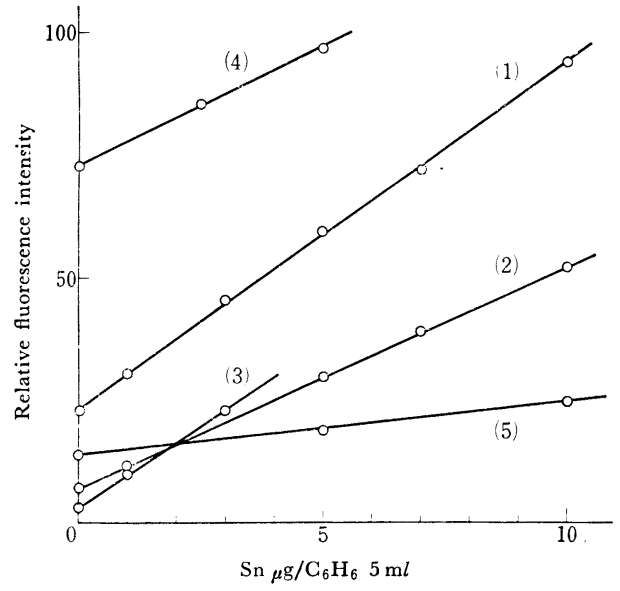

Fig. 7 Calibration curves for tin

(1) $\mathrm{HBr}-\mathrm{C}_{6} \mathrm{H}_{6}$ system, $565 \mathrm{~m} \mu / 580 \mathrm{~m}_{\mu}, 20$ div. with the Rhodamine B reference solution $(0.168 \mu \mathrm{g} / \mathrm{ml})$; (2) $\mathrm{HBr}-\mathrm{C}_{6} \mathrm{H}_{5} \mathrm{CH}_{3}, 565 \mathrm{~m} \mu / 580 \mathrm{~m} \mu, 20$ div.; (3) $\mathrm{HBr}-\mathrm{C}_{6} \mathrm{H}_{4}\left(\mathrm{CH}_{3}\right)_{2}, 560 \mathrm{~m} \mu / 575 \mathrm{~m} \mu, 20$ div.; (4) $\mathrm{HCl}-\mathrm{C}_{6} \mathrm{H}_{6}, 560 \mathrm{~m} \mu / 575 \mathrm{~m} \mu, 10$ div.; (5) $\mathrm{HCl}$ $\mathrm{C}_{6} \mathrm{H}_{5} \mathrm{CH}_{3}, 555 \mathrm{~m}_{\mu} / 570 \mathrm{~m}_{\mu}, 20 \mathrm{div}$.

\section{7 共存塩の影響}

スズ $10 \mu \mathrm{g}$ をとり， $2 N$ 臭化水素酸-ベンゼン系で定 量する際の共存イオンの影響を調査した結果を Table II に示した.

Table II Effect of diverse ions

\begin{tabular}{|c|c|c|c|}
\hline \multicolumn{2}{|c|}{ Ions $(\mu \mathrm{g})$} & \multirow{2}{*}{$\frac{\text { Added as }}{\mathrm{ZnSO}_{4}}$} & \multirow{2}{*}{$\frac{\text { Sn found } t(\mu \mathrm{g})}{10.1_{7}}$} \\
\hline $\mathrm{Zn}^{2+}$ & 100 & & \\
\hline $\mathrm{Cu}^{2+}$ & 100 & $\mathrm{CuSO}_{4}$ & $10.0_{0}$ \\
\hline $\mathrm{Hg}^{2+}$ & 100 & $\mathrm{HgCl}_{2}$ & $14.0_{3}$ \\
\hline $\mathrm{Be}^{2+}$ & 100 & $\mathrm{BeSO}_{4}$ & $10.3_{5}$ \\
\hline $\mathrm{Ni}^{2+}$ & 100 & $\mathrm{NiSO}_{4}$ & $10.7_{0}$ \\
\hline $\mathrm{Mg}^{2+}$ & 100 & $\mathrm{MgSO}_{4}$ & $10.3_{5}$ \\
\hline $\mathrm{UO}_{2}{ }^{2+}$ & 100 & $\mathrm{UO}_{2}\left(\mathrm{CH}_{3} \mathrm{COO}\right)_{2}$ & $7.8_{9}$ \\
\hline $\mathrm{Y}^{3+}$ & 100 & $\mathrm{YCl}_{3}$ & $8.9_{8}$ \\
\hline $\mathrm{Sc}^{3+}$ & 100 & $\mathrm{ScCl}_{3}$ & $8.9_{4}$ \\
\hline $\mathrm{Al}^{3+}$ & 100 & $\mathrm{Al}_{2}\left(\mathrm{SO}_{4}\right)_{3}\left(\mathrm{NH}_{4}\right)_{2} \mathrm{SO}_{4}$ & $8.2_{0}$ \\
\hline $\mathrm{Bi}^{3+}$ & 100 & $\mathrm{BiCl}_{3}$ & $8.2_{4}$ \\
\hline $\mathrm{Cr}^{6+}$ & 100 & $\mathrm{~K}_{2} \mathrm{CrO}_{4}$ & $6.3_{1}$ \\
\hline $\mathrm{Fe}^{3+}$ & 100 & $\mathrm{FeCl}_{3}$ & $9.2_{1}$ \\
\hline $\mathrm{As}^{3+}$ & 100 & $\mathrm{Na}_{3} \mathrm{AsO}_{3}$ & $8.5_{9}$ \\
\hline $\mathrm{B}^{3+}$ & 100 & $\mathrm{H}_{3} \mathrm{BO}_{3}$ & $10.1_{7}$ \\
\hline $\mathrm{V}^{5+}$ & 100 & $\mathrm{NH}_{4} \mathrm{VO}_{3}$ & $7.8_{9}$ \\
\hline $\mathrm{W}^{6+}$ & 100 & $\mathrm{Na}_{2} \mathrm{WO}_{4}$ & $12.9_{8}$ \\
\hline $\mathrm{Mo}^{6+}$ & 100 & $\left(\mathrm{NH}_{4}\right)_{6} \mathrm{Mo}_{7} \mathrm{O}_{24}$ & $8.5_{9}$ \\
\hline $\mathrm{Ga}^{3+}$ & 50 & $\mathrm{GaCl}_{3}$ & $9.3_{7}$ \\
\hline $\mathrm{Sb}^{3+}$ & 50 & $\mathrm{SbCl}_{3}$ & $8.6_{0}$ \\
\hline $\mathrm{Cd}^{2+}$ & 50 & $\mathrm{CdCl}_{2}$ & $9.7_{6}$ \\
\hline $\mathrm{Au}^{3+}$ & 10 & $\mathrm{HAuCl}_{4}$ & $4.8_{4}$ \\
\hline $\mathrm{Tl}^{3+}$ & 5 & $\mathrm{TlCl}_{3}$ & +++ \\
\hline $\mathrm{In}^{3+}$ & 5 & $\mathrm{InCl}_{3}$ & +++ \\
\hline
\end{tabular}

$\dagger 10 \mu \mathrm{g}$ of tin was taken; +++ Serious positive interference
Table II よりわかるように金, クロムは大きな負誤 差を, タリウム, インジウム, 水銀, タングステンが正 誤差を与え妨害する．特にタリウム（III)，インジウム は同条件下では強いけい光を発するのでその共存は許さ れない。したがって臭化水素酸一ベンゼン系を用いた口 ーダミンBによるスズのけい光定量においてはこれらの 妨害する諸イオンをあらかじめ適当な前処理により分離 しておく必要がある。

この場合，スズを $0.3 N$ 塩酸酸性溶液から硫化水素に より硫化物として沈殿させインジウム, 金などより分離 することができる. またタりウムとの分離には臭化水素 酸一ベンゼン系ローダミン B イオン会合体の抽出時の酸 濃度を調節する方法が好つごうであった。

硫化水素による分離 : スズ $10 \mu \mathrm{g}$ にこれら金属イオ ンの一定量を添加し, $0.3 N$ 塭酸酸性溶液として硫化水 素ガスを通じ, 沈殿をガラスフィルターで沪過後, 王水 に溶解する，この溶液をほとんど蒸発乾固したのち，本 法によりスズを定量し, 硫化物としてのスズの分離効果 を検討した，との結果を Table III に示した. スズの 少ない試料溶液については担体としてカドミウムイオン $50 \mu \mathrm{g}$ 程度を添加し，硫化カドミウムにスズを共沈濃縮 すればよい. Table III よりわかるようにタリウムはス ズと共沈し妨害する。したがってスズをタリウムより分 離する必要がある.

Table III Recovery of tin by sulfide precipitation

\begin{tabular}{|c|c|c|c|}
\hline $\begin{array}{c}\text { Sn taken } \\
(\mu \mathrm{g})\end{array}$ & $\begin{array}{l}\text { Diverse ion } \\
(\mu \mathrm{g})\end{array}$ & $\begin{array}{l}\text { Sn found } \\
(\mu \mathrm{g})\end{array}$ & $\begin{array}{l}\text { Recovery } \\
(\%)\end{array}$ \\
\hline 10 & - & 9.8 & 98 \\
\hline 10 & $\operatorname{In}^{3+} \quad 10$ & 10.8 & 108 \\
\hline 10 & $\mathrm{Au}^{3+} \quad 16$ & 10.1 & 101 \\
\hline 10 & $\mathrm{Tl}^{3+}$ & 12.0 & 120 \\
\hline 10 & $\mathrm{Cd}^{2+} \quad 50$ & 9.8 & 98 \\
\hline 10 & $\mathrm{Cd}^{2}+500$ & 8.5 & 85 \\
\hline
\end{tabular}

タリウムとスズの抽出分離 : インジウム, タリウム, 金，スズの臭化水素酸-ローダミン B イオン会合体を ベンゼン抽出する際の酸濃度とけい光強度との関係を Fig. 8 に示す. これよりわかるように $4 N$ 臭化水素酸 酸性よりローダミンB-ブロモタレイトイオン会合体を 抽出分離 $(2 \sim 3$ 回抽出), 水相の酸濃度を $2 N$ 臭化水 素酸酸性として，スズーローダミン B イオン会合体をべ ンゼンで抽出しけい光定量すればタリウムの影響を免れ ることができた. この方法により各種濃度のタリウムと 共存するスズを定量した結果を Table IV に示した. タリウム量の少ない試料では $4 N$ 臭化水素酸酸性よりの 


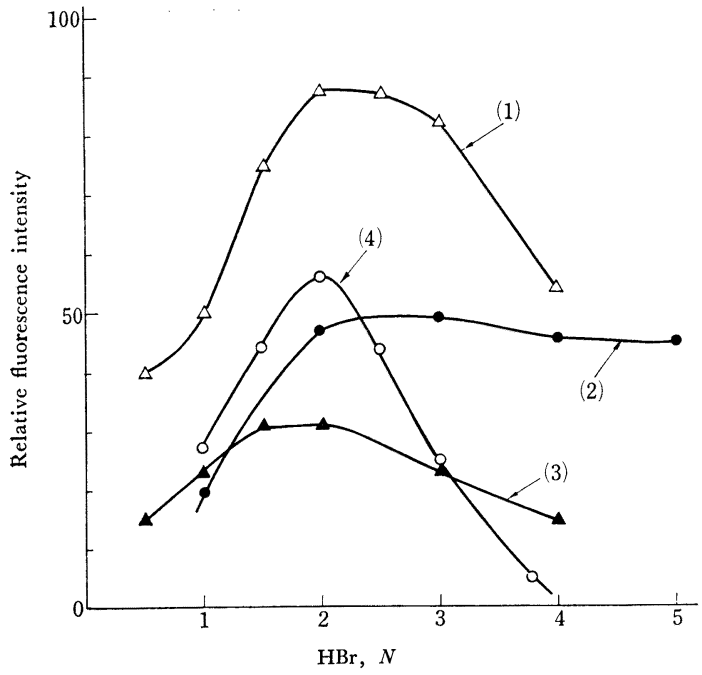

Fig. 8 Effect of hydrobromic acid concentration on fluorescence intensity

(1) In $0.5 \mu \mathrm{g},(570 \mathrm{~m} \mu / 585 \mathrm{~m} \mu, 30$ div.); (2) $\mathrm{Tl}$ (III) $0.5 \mu \mathrm{g},(565 \mathrm{~m} \mu / 585 \mathrm{~m} \mu, 30$ div. $)$; (3) Au $0.5 \mu \mathrm{g}$, $(565 \mathrm{~m} \mu / 585 \mathrm{~m} \mu, 30 \mathrm{div}$.$) ; (4) Sn 20.0 \mu \mathrm{g},(565 \mathrm{~m} \mu /$ $580 \mathrm{~m} \mu, 10$ div.)

Table IV Separation of tin from thallium by the extraction method

\begin{tabular}{ccc}
\hline \hline Sn taken $(\mu \mathrm{g})$ & Tl added $(\mu \mathrm{g})$ & Sn found $(\mu \mathrm{g})$ \\
\hline 10 & - & 10.0 \\
10 & 5 & 9.8 \\
10 & 10 & 9.9 \\
10 & 50 & 10.1 \\
\hline
\end{tabular}

抽出操作は 1 回でじゅうぶえであるが，タリウム量の多 いときは少なくとも 3 回注抽出をくりか立必要があ る.

\section{4 煙灰中のスズの定量}

硫化物沈殿分離ならびにスズとタりウムの抽出分離法 它併用すれば共存妨害イオンの影響より容易に免れう る.したがって本法の応用例の一つとして銅精練行程よ り得られた煙灰試料中のスズの定量を行なった.

粉末試料 $0.1 \mathrm{~g}$ を王水に溶解し, 蒸発乾固したのち, $0.3 N$ 塩酸酸性溶液として硫化水素ガスをじゅうぶん通 す. 硫化物沈殿をガラスフィルターで沪過し, 沈殿を $5 \sim 10 \mathrm{ml}$ の王水に溶解する. 溶液を蒸発乾固後, 残留 物を $4 N$ 臭化水素酸に溶解し， $0.5 \%$ ローダミン B 溶 液 $1.5 \mathrm{ml}$ を加光, ベンゼン $5 \mathrm{ml}$ で抽出する（要すれ ばこの抽出操作を $2 \sim 3$ 回くりかえす). 水相を $2 N$ 臭
化水素酸酸性になるように 希釈し（全容約 $10 \mathrm{ml}$ とす る)， $0.5 \%$ ローダ そン B 溶液 $1.5 \mathrm{ml}$ を加える.これを ベンゼン $5 \mathrm{ml}$ で抽出し，3.6 の条件により Fig. 7 の 検量線でスズを定量する.銅精練行程で得られた煙灰試 料 2 種につき，本法によりスズを分析した結果を Table Vに示した。

Table V Determination of tin in flue dust

\begin{tabular}{lllrl}
\hline \multicolumn{1}{c}{ Sample } & $\begin{array}{c}\text { Taken } \\
(\mathrm{g})\end{array}$ & $\begin{array}{c}\text { Aliquot } \\
(\mathrm{mg})\end{array}$ & $\begin{array}{c}\text { Sn } \\
\text { found } \\
(\mu \mathrm{g})\end{array}$ & $\begin{array}{c}\text { Sn } \\
\text { content } \\
(\%)\end{array}$ \\
\hline $\begin{array}{c}\text { Copper converter back } \\
\text { collector dust (Mitsui }\end{array}$ & 0.1 & 0.4 & 8.7 & 2.18 \\
$\begin{array}{l}\text { Co. Hibi) } \\
\text { Copper converter Cottrell } \\
\text { dust (Mitsubishi Co. }\end{array}$ & 0.1 & 0.8 & 16.4 & 2.05 \\
$\quad$ Naoshima) & & 2.4 & 6.1 & 0.85 \\
\hline
\end{tabular}

本法によれば $0.1 \mathrm{~g}$ の試料を用いて $0.1 〜 2 \%$ のスズ が迅速簡便に定量できる.

(1969 年 4 月, 日本化学会第 22 年会において発表)

\section{交献}

1) E. B. Sandell : " Colorimetric Determination of Traces of Metals", 3rd Ed., p. 854 (1959), (Interscience Publishers Ltd., London).

2) 石橋雅義, 重松恒信, 山本勇簏, 井上泰 : 本 誌, 7, 473 (1958).

3) C. F. Coyle, C. E. White : Anal. Chem., 29, 1486 (1957).

4) L. B. Ginzburg, E. P. Shkrobot : Zavodsk. Lab., 23, 527 (1957).

5) 向井孝一, 望月 豊: 本誌, 17, 452 (1968).

6) R. T. Arnesen : Anal. Chim. Acta, 33, 335 (1965).

7) H. Onishi, E. B. Sandell : ibid., 13, 159 (1955).

8) H. Onishi : Bull. Chem. Soc. Japan, 30, 827 (1957).

9) B. T. Taskarin, D. P. Shcherbov : Khim. khim. Teckhnol., 3-4, 208 (1965); Anal. Abstr., 14, 4559 (1967).

10) E. Eegriwe : Z. anal. Chem., 70, 400 (1927).

11）水谷三郎，中山豪一，森川 泰：“試薬および溶 媒”（基礎分析化学講座，3)，p. 84 (1966)，（共 立出版).

$$
\grave{s}
$$

Fluorometric determination of tin with Rhodamine B. Yasuharu Nishikawa, Keizō Hiraki, Takeshi Naganuma and Shozō Ninsa (Department of Chemistry, Faculty of Science and Technology, Kinki University, Kowakae, Higashiosaka-shi, Osaka-fu)

Rhodamine $B$ reacts with tin(IV) in a hydrobromic acid medium to form a Rhodamine B-tin complex with reddish orange fluorescence, and was used as a reagent for the fluorometric determination of tin. Several conditions for the excitation and emission 
spectra, the kind of acid and solvent, the effect of concentration of acid, concentration of reagent and the effect of diverse ions were investigated.

For the determination of tin, $1.5 \mathrm{ml}$ of $0.5 \%$-Rhodamine $B$ solution was added to the sample solution containing $0.5 \sim 10 \mu \mathrm{g}$ of tin, and the acid concentration was adjusted to $2 \mathrm{~N}$ with hydrobromic acid (final volume $5 \mathrm{ml}$ ). The Rhodamine B-tin complex was extracted with $5 \mathrm{ml}$ of benzene. The organic phase was separated and centrifuged, and its fluorescence intensity was measured at $580 \mathrm{~m} \mu$ against the reference Rhodamine iB solution $(0.168 \mu \mathrm{g} / \mathrm{ml})$. Auric ion, $\mathrm{Cr}^{6+}, \mathrm{Tl}^{3+}, \mathrm{In}^{3+}, \mathrm{Hg}^{2+}$ and $\mathrm{WO}_{4}{ }^{2-}$ interfered.

The method is simple and accurate for the determination of tin. The sensitivity of the method was $0.1 \mu \mathrm{g} \mathrm{Sn} / \mathrm{ml}$ benzene.

(Received Feb. 16, 1970)

\title{
ジメチルスルホナゾ III を指示薬とする燃料ガス中の 全イオウの定量
}

\author{
笠原 三千世，板 原 毅*
}

(1970 年 2 月 16 日受理)

\begin{abstract}
燃料ガスを燃焼させて生成するイオウの酸化物を過酸化水素水に吸収させて硫酸とし，これをジメチ ルスルホナゾ III を指示薬として塩化バリウム溶液で滴定して, 試料ガス中の全イオウ分を定量する方 法について論じた.

この指示薬は滴定の終点における变色が鋭敏であり, 色調も赤紫色から緑青色に変わるので, 同系統 のトリンやアルセナゾ III 指示薬よりもはるかに終点が見分けやすい，

硫酸イオン量が少ない場合でも，塩化カリウム溶液の添加により，滴定時の呈色の復帰速度を大きく することができ，から試験值も小さいので，定量下限はイオウとして $0.05 \mathrm{mg}$ の微量まで分析できる. 再現性は変動倸数で $\pm 1.5 \%$ であった。
\end{abstract}

\section{1 緒言}

燃料ガス中の全イオウの定量法としては，一般に燃焼 させて生成するイオウの酸化物を過酸化水素水沉吸収さ せ，硫酸として定量する方法が用いられている。

硫酸イオンの定量法としては, 比濁法1), クロラニル 酸法2), 亜鉛-EDTA 法3), トリン法4), アルセナゾ III 法5)など多くの方法がある.しかしこれらの方法は，分 析操作が複雑であったり，滴定の終点が見分けにくいな どの短所がある.

そこで，トリンやアルセナゾIII と同系の指示薬であ るジメチルスルホナゾIII を用い，塩化バリウム溶液で 滴定する方法について検討した結果, 前記の諸方法に比 ベて，操作が簡単で終点の変色が鋭敏で非常に見分けや すく滴定可能な濃度範囲も広く, 微量まで正確に分析で きることを確認したので報告する。

* 大阪瓦斯株式会社総合研究所 : 大阪市此花区酉島町 9 丁目
2 分 析 法

\section{$2 \cdot 1$ 試 薬}

（1）過酸化水素水（3\%）：かっ色びえにたくわえ る.

(2) エチルフルコール $(95 \mathrm{v} / \mathrm{v} \%)$.

(3) ブロムクレゾールグリーン溶液 $(0.04 \mathrm{w} / \mathrm{v} \%)$ : ブロムクレゾールグリーン $0.04 \mathrm{~g}$ をエチルアルコール $(95 \mathrm{v} / \mathrm{v} \%) 20 \mathrm{ml}$ に溶かし水を加えて $100 \mathrm{ml}$ とする.

(4) アンモニア水 $(1+200)$.

(5) アセトン.

(6) ジメチルスルホナゾ III 溶液 $(0.1 \mathrm{w} / \mathrm{v} \%)$ : ジ メチルスルホナゾ III $\{4,5$-dihydroxy-3, 6-bis-[(2sulfo-4-methylphenyl) azo]-2, 7-naphthalene disulfonic acid, tetra sodium salt\}（以下 DMS III と略記）同 仁薬化学製 $0.02 \mathrm{~g}$ を水 $20 \mathrm{ml}$ に溶かす.

DMS III の構造式は次に示すとおりである.<smiles>Cc1ccc(N=NN=C2C(O)=C3C(=CC([N+](=O)[O-])=C3O)C(O)=C2N=Nc2ccc(C)cc2[N+](=O)[O-])c([N+](=O)[O-])c1</smiles> 